\title{
THE SURGICAL TREATMENT OF SUBSTERNAL GOITER
}

\author{
LORI FRITTS, MD, NORMAN W. THOMPSON, MD
}

\begin{abstract}
Substernal goitcr remains a common consideration in the differential diagnosis of a mediastinal mass. Given the potential for serious goiter-related complications as well as the inability to rule out associated malignancy, it has been our policy to treat all substernal goiters surgically over the past 20 years. During the period from 1972 to 1992, 101 patients with the major component of their goiters below the thoracic inlet underwent thyroidectomy. The most common symptoms were related to airway compression (82\%) and dysphagia (37\%). In addition, there was a $13 \%$ incidence of malignancy and a similar occurrence of thyrotoxicosis in this group of patients. Although total thyroidectomy was performed only for malignant goiters during the first decade, $71 \%$ of patients had total thyroidectomies during the second and, with a few exceptions, all procedures were done through a cervical incision. No patient developed permanent hypoparathyroidism, although two developed permanent unilateral vocal cord palsies. Surgical treatment is a safe procedure with rare mortality (none in this series) and low morbidity. Total thyroidectomy was not associated with added morbidity and it eliminates the possibility of recurrent goiter.
\end{abstract}

Throughout the past 75 years, there has been a progressive decline in the incidence of multinodular goiter in the United States. Furthermore, as pointed out by Shambaugh et al, ${ }^{1}$ fewer patients are presenting for initial medical evaluation with massive goiters. The central factor thought to be responsible for this decline is increased American dietary iodine, particularly since the introduction of iodized salt. Other probable contributing factors include (1) the increasing use of levothyroxine with intent to suppress goitrogenic growth, and (2) the availability of sophisticated imaging studies to facilitate earlier diagnosis and, in turn, earlier intervention.

Despite its diminishing frequency, substernal multinodular goiter must remain a common consideration in the differential diagnosis of a mediastinal mass. Left unattended, substernal goiters often cause disabling symptoms and can lead to life-threatening airway obstruction.

The reported incidence of substernal goiter ranges from $2.6 \%$ to $21 \%$ of patients having thyroidectomies (Table 1 ). The wide variation is undoubtedly influenced by regional endemic goiter belts and referral patterns, as most series have been collected at tertiary care institutions.

The difficult task of determining the true incidence of substernal goiter is complicated by the lack of a standardized definition throughout the medical literature. In 1945, Lahey ${ }^{13}$ proposed that substernal goiters were glands "in which the greatest diameter of the intrathoracic mass by roentgenogram is well below the upper aperture of the thoracic cage made by the sternum, first rib and vertebral bodies." Wakeley and Mulvany ${ }^{3}$ classified substernal goiters into three groups: (1) a "small

From the Division of Endocrine Surgery, Department of Surgery, University of Michigan Medical Center, Ann Arbor.

Address reprint requests to Lori Fritts, MD, University of Michigan Hospital, Department of General Surgery, 1500 E Medical Center Dr, Ann Arbor, MI 48109.

Copyright (c) 1994 by W.B. Saunders Company

1043-1810/94/0503-0009\$05.00/0 substernal extension" of a mainly cervical goiter (most common in their series), (2) "partial" intrathoracic goiter with a major portion of the gland located within the thorax, and (3) "complete" intrathoracic goiter in which the entire gland lies within the thorax.

It is our opinion that all substernal goiters should be treated surgically and that their presence alone is an indication for resection. Given the potential for serious goiter-related complications as well as the inability to accurately rule out associated malignancy, we support thisopinion with the following results of our 20-year clinical experience with substernal goiter.

\section{CLINICAL MATERIAL}

A review of 1,992 patients undergoing thyroidectomy at the University of Michigan from 1972 to 1992 identified 101 patients with substernal goiters. In each of these, the major component of the thyroid enlargement was below the thoracic inlet (Wakeley and Mulvany: Type 2 or 3). This group of patients comprised $5.1 \%$ of all patients undergoing thyroidectomy during this time period. The incidence during the first decade was $5.7 \%$ and decreased to $4.5 \%$ during the most recent decade. The patients ranged in age from 23 to 87 years with a mean age of 64 years. There were 75 women and 26 men, yielding a female:male ratio of 2.9:1.

Thirteen patients $(12.9 \%)$ were hyperthyroid at initial presentation, all due to toxic multinodular goiter. None of the patients had Graves' disease. All other patients $(87.1 \%)$ were clinically and biochemically euthyroid or mildly hypothyroid.

Malignant thyroid neoplasms were identified in 13 patients $(12.9 \%)$. All were ultimately treated with total thyroidectomy except for 1 patient with anaplastic carcinoma whose disease precluded complete removal of the gland. A formal neck dissection accompanied thyroidectomy in 1 patient with medullary carcinoma as well as 
in 1 patient with papillary carcinoma who required sternotomy and neck incision to remove his goiter. One patient underwent an extensive mediastinal node dissection in addition to resection of a completely intrathoracic goiter containing Hurthle-cell carcinoma. Incidental benign neoplasms included a large follicular adenoma (10 $\mathrm{cm}$ in diameter) within a multinodular goiter and three parathyroid adenomas. One patient was diagnosed with Pendred's syndrome.

The most common symptoms reported were those associated with tracheal compression. Eighty-three patients (82\%) complained of dyspnea, cough, wheezing, or nocturnal dyspnea. Thirty-seven patients $(36.6 \%)$ reported significant dysphagia. Progressive hoarseness or voice changes were noted by $14(13.9 \%)$ patients. Three patients reported weight loss as their primary symptom and 4 patients presented with chest pain. Two patients required emergency thyroidectomy for acute respiratory compromise. Superior vena cava obstructive signs were present in 14 patients (13.9\%). Many patients with symptoms were aware of their enlarged thyroid glands for 15 to 20 years before seeking surgical intervention.

Preoperative evaluation routinely included chest roentgenogram, electrocardiogram, and thyroid function tests (Fig 1). When compared with patients treated surgically for goiter from 1972 to 1982, patients treated from 1982 to 1992 were much more likely to undergo preoperative computed tomography (CT) (74.5\%) (Figs 2-4). A reciprocal decrease in the frequency of radioisotope scanning was also noted. Unlike the routine use of diagnostic radioiodine scanning in nearly all patients during the first decade, only $51 \%$ of second decade patients underwent any isotope imaging. Barium swallow, pulmonary function testing, fine needle aspiration, and bronchoscopy were used only in selective cases.

Eighteen patients $(17.8 \%$ ) had undergone a previous thyroid resection, most often for symptomatic diffuse glandular enlargement or discrete nodules. Fifteen patients had had a lobectomy and 3 patients had subtotal resections performed at other hospitals an average of 20 years before surgical treatment at the University of Michigan.

Nearly half of all patients had been taking suppressive doses of thyroid hormone preoperatively. Propylthiouracil had been used in 3 patients and radioactive iodine recently administered to 2 patients to control their hyperthyroidism before referral for surgery. Two patients had previously been treated with radioiodine for thyrotoxicosis. One patient had been exposed to previous head and neck irradiation for chronic tonsillitis.

TABLE 1. Incidence of Substernal Goiters

\begin{tabular}{|c|c|c|c|}
\hline Study & $\begin{array}{l}\text { Total } \\
\text { Thyroidectomies }\end{array}$ & $\begin{array}{l}\text { Substernal } \\
\text { Goiters }\end{array}$ & Incidence \\
\hline $\begin{array}{l}\text { Lahey and Swinton }{ }^{2} \\
\text { Wakeley and Mulvany } \\
\text { McCort }^{3} \\
\text { Pemberton } \\
\text { Reeve }^{6} \\
\text { DeAndrade } \\
\text { Allo and Thompson } \\
\text { Shaha et al } \\
\text { Maruotti et al }^{9} \\
\text { Wax and Briant } \\
\text { Sanders et al } \\
\text { Fritts and Thompson }\end{array}$ & $\begin{array}{r}5,131 \\
1,265 \\
908 \\
4,006 \\
2,000 \\
9,100 \\
872 \\
370 \\
1,103 \\
938 \\
646 \\
1,992\end{array}$ & $\begin{array}{r}1,086 \\
111 \\
23 \\
542 \\
173 \\
1,300 \\
50 \\
72 \\
51 \\
24 \\
52 \\
101\end{array}$ & $\begin{array}{r}21.0 \% \\
8.7 \% \\
3.0 \% \\
13.5 \% \\
8.6 \% \\
14.2 \% \\
5.7 \% \\
19.0 \% \\
4.6 \% \\
2.6 \% \\
8.0 \% \\
5.2 \%\end{array}$ \\
\hline
\end{tabular}

* Reported as total number of thyroidectomies specifically for goiter.

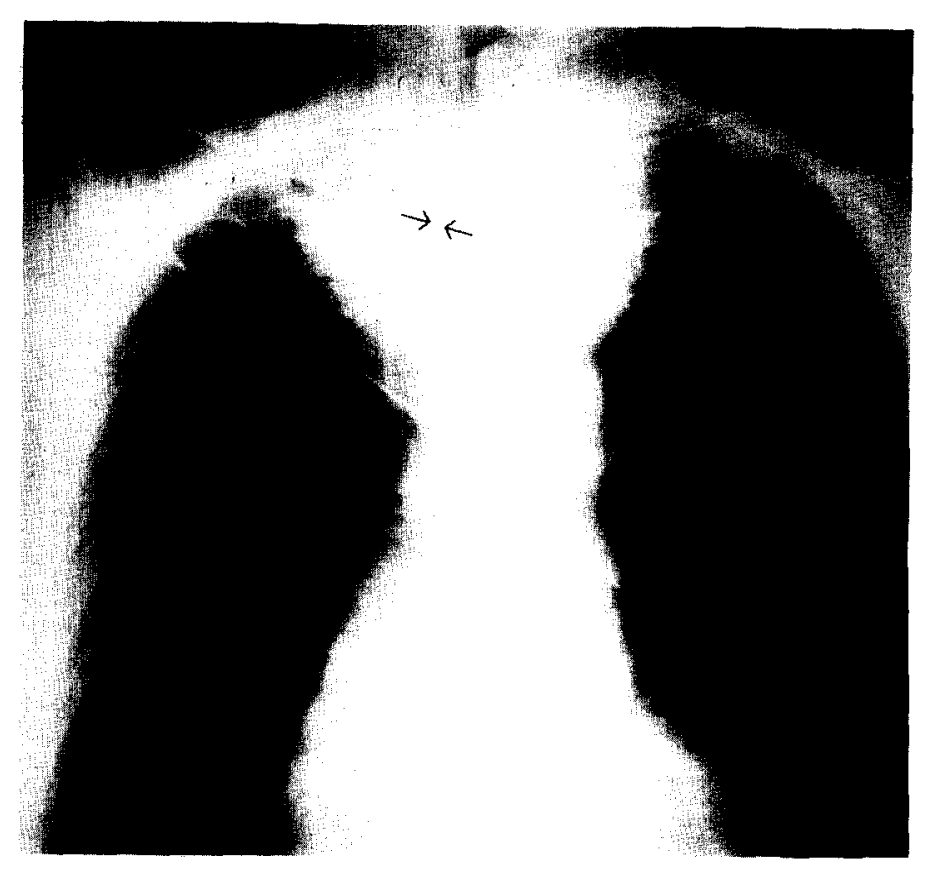

FIGURE 1. Standard posterior-anterior chest roentgenogram showing large substernal goiter causing symptomatic tracheal narrowing at the thoracic inlet and deviation from left to right.

\section{SURGICAL MANAGEMENT}

The majority of patients in this series had substernal goiters that would be typed as "partial" using the classification system proposed by Wakeley and Mulvany in $1940 .^{3}$ The major portion of the glandular enlargement was located within the thorax, although a connection with the cervical gland component was preserved. Most had anterior mediastinal goiters but $6(5.9 \%)$ had posterior mediastinal goiters. Only 1 patient had a completely intrathoracic goiter without any identifiable connection to a histopathologically unremarkable cervical thyroid gland.

From 1972 to 1982 , all patients with benign goiters underwent either lobectomy and isthmusectomy for unilateral gland enlargement or a subtotal thyroidectomy when the contralateral cervical lobe was diffusely enlarged. Total thyroidectomy was limited to the 8 patients $(16 \%)$ found to have malignant disease. Patients treated subsequent to 1982 were more likely to undergo total thyroidectomy. Twenty-two patients (43\%), including 5 with malignancy, underwent complete gland removal at the time of initial operation. An additional 14 patients $(27.5 \%)$ with benign goiters underwent completion total thyroidectomy at the University of Michigan, 10 having had previous lobectomies and 4 having had previous subtotal resections at other institutions. Thus, 36 of 51 patients $(71 \%)$ underwent total thyroidectomy either as a primary or completion procedure during the second decade of this study.

Eight patients had unilateral gland enlargement that was amenable to total lobectomy and isthmusectomy. Seven patients were treated with subtotal thyroidectomy as a bilateral procedure.

All patients were placed on levothyroxine replacement or suppression therapy postoperatively. Two patients with papillary carcinoma were treated with iodine 131 postoperatively. One patient with a Hurthle-cell carcinoma underwent external beam radiotherapy following resection.

All patients but 1 underwent an initial thyroid explo- 


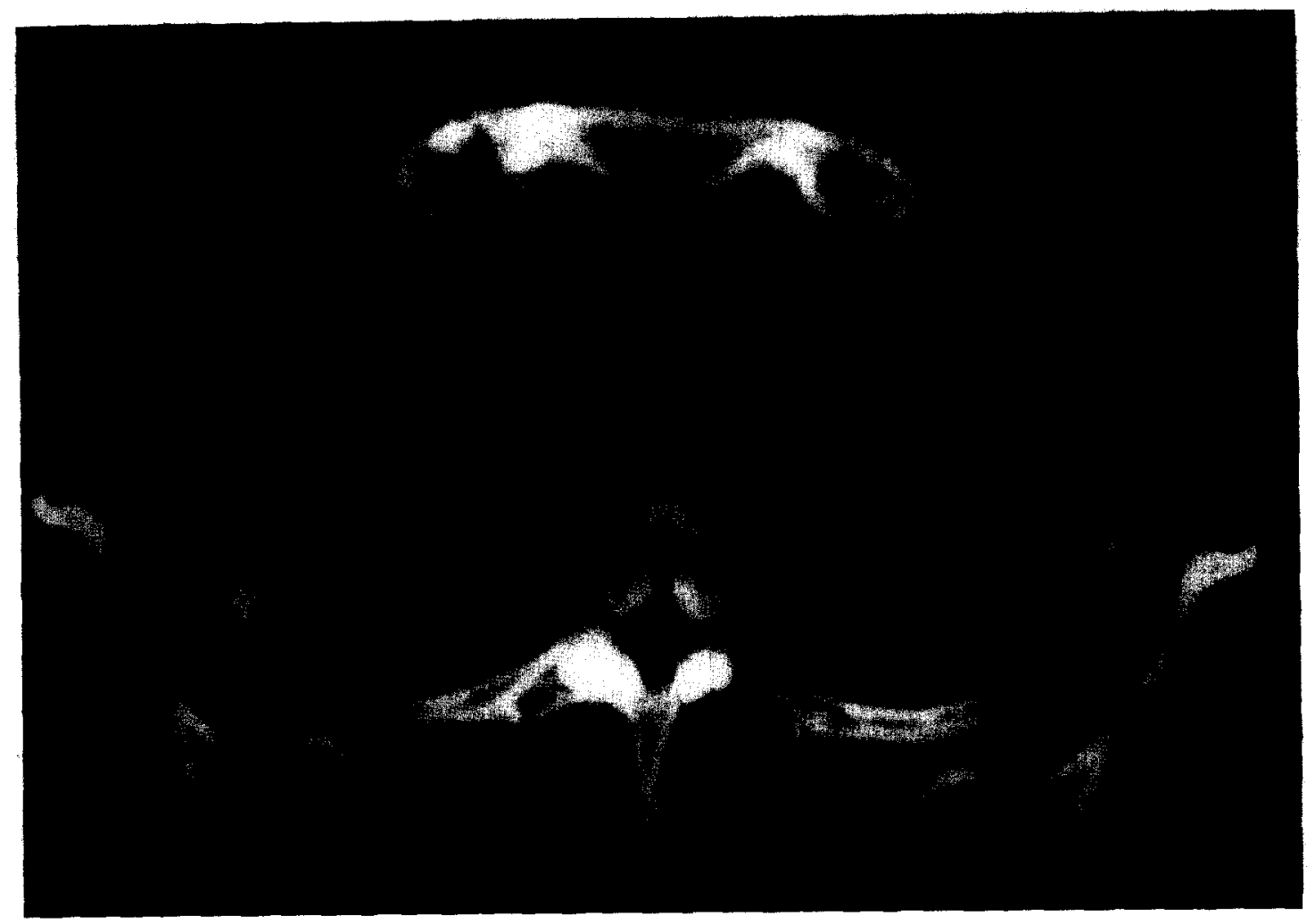

FIGURE 2. CT scan showing moderate tracheal compression by multinodular goiter. Substernal components involved both lobes, located circumferentially around the trachea, which was deviated to the right by the larger left lobe.

FIGURE 3. CT scan showing substernal tumor mass

descending to the aortic arch. Primary tumor was a papillary carcinoma measuring $10 \mathrm{~cm}$ in diameter.

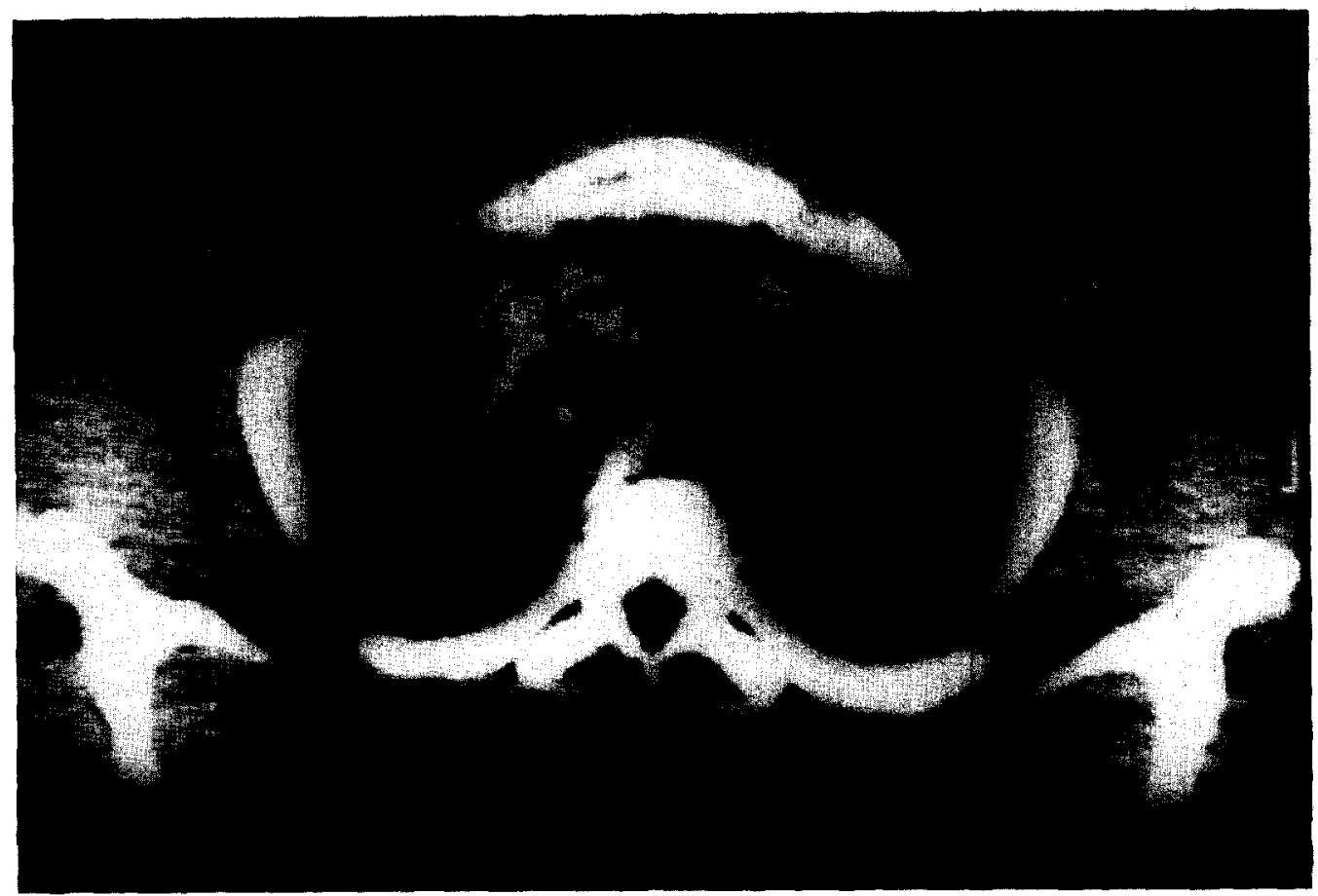

ration through a cervical incision. Sternotomy was required in only three cases to facilitate goiter removal. One patient was a 68 -year-old woman with chest pain who was found by CT scan to have a mediastinal mass. The mass was mistakenly diagnosed as a thymoma and her operation was performed by the cardiothoracic service. A completely intrathoracic goiter with foci of Hurthle-cell carcinoma was found. This patient subsequently underwent a total cervical thyroidectomy as well, although as a secondary procedure. The second patient requiring sternotomy was a 73-year-old man with airway obstruction and a severe superior vena cava syndrome caused by his goiter. He had had previous tuberculosis, which was felt to contribute to the dense adhesions between the pleura and the intrathoracic portion of his gland. These adhesions coupled with severe venous en- gorgement precluded a safe excision of his gland through the cervical incision alone. The third patient was a 58year-old man with papillary carcinoma within an extremely large goiter associated with marked desmoplastic reaction within the anterior mediastinum.

Tracheostomies were performed in 2 patients with long-standing airway obstruction. These patients required urgent preoperative endotracheal intubation and had significant laryngeal edema. Both tracheostomy tubes were removed within 2 weeks of their thyroidectomies. One patient was treated with tracheal suspension to the midline strap muscle closure because of apparent tracheal instability and kinking (Fig 5). No patient developed a wound infection but 1 patient did develop a sizable seroma that required several aspirations. One patient developed a large hematoma in the operative site 
FIGURE 4. CT scan showing severe tracheal compression by benign goiter involving both lobes. The larger right lobe deviated trachea to the left.

approximately 8 hours after operation requiring emergency wound exploration and evacuation of clot. There was no operative mortality.

In 2 patients, a lower pole parathyroid gland was resected along with the goiter because of its location. The parathyroid gland was then minced and transplanted into a sternocleidomastoid muscle. In each case, the remaining parathyroid glands had been preserved and appeared viable. Neither patient developed postoperative hypocalcemia.

Permanent unilateral vocal cord palsy occurred in two patients (2\%) and was verified by laryngoscopy. In neither case was the nerve felt to have been transected or clamped but restoration of nerve function had not occurred at the time of follow-up (Fig 6). No cases of permanent hypoparathyroidism occurred. Temporary hypocalcemia, requiring oral calcium and/or vitamin $D$ therapy, had occurred in 13 patients $(12.9 \%)$. One of these patients had had a parathyroid adenoma removed at the

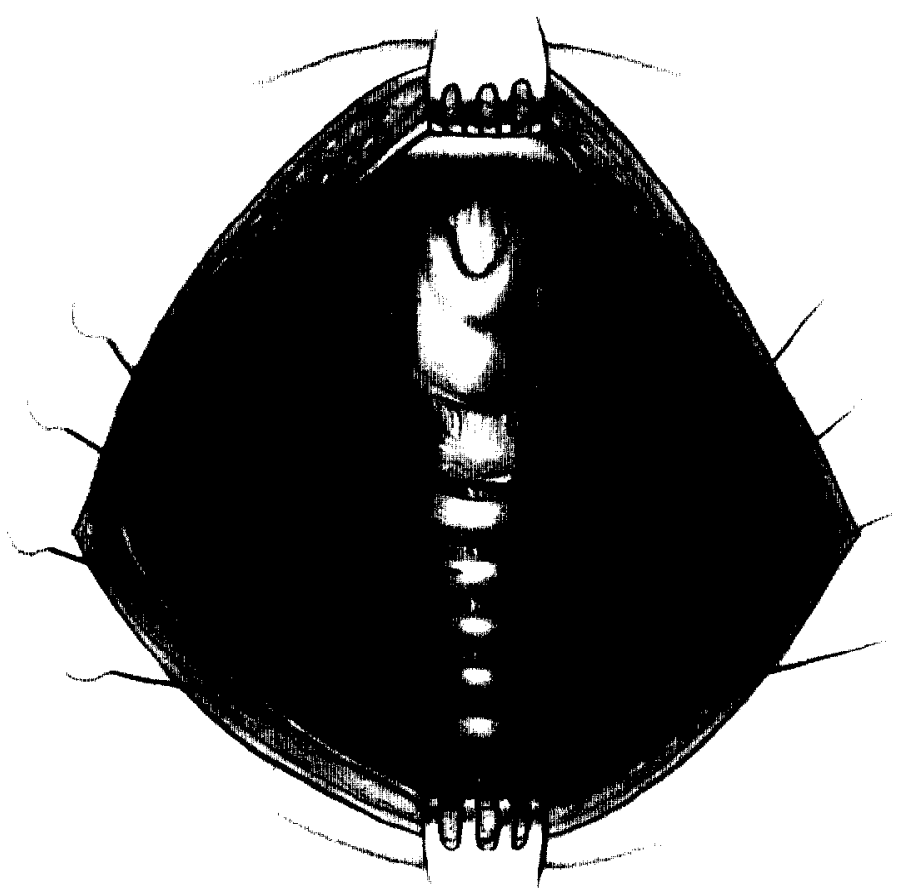

FIGURE 5. Technique for tacking or suspending an elongated or compressed trachea in the midline after thyroidectomy. Absorbable sutures are placed into the pretracheal fascia or tracheal rings as the strap muscles are reapproximated in the midline.

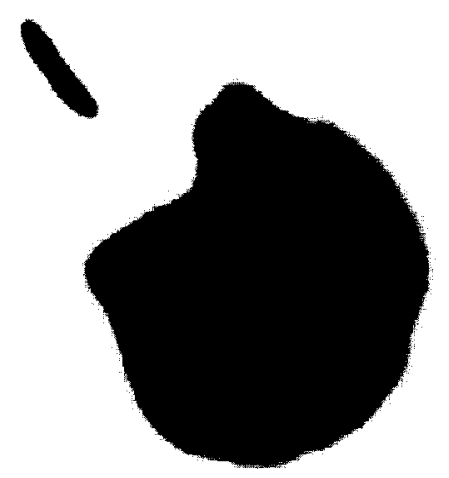

time of the substernal goiter excision that may have contributed to her suppressed parathyroid function postoperatively. Four of the remaining 12 patients had undergone thyroid resection elsewhere and the status of their parathyroid glands could not be fully determined.

\section{OPERATIVE TECHNIQUE}

A transverse collar incision was used in all cases to explore the thyroid gland (Fig 7). Before any manipulation of the substernal component, the anterior suspensory ligament and pyramidal lobe were mobilized to the level of isthmus. The superior pole was mobilized on the side of a unilateral goiter or bilaterally in the setting of diffuse glandular enlargement. After dividing and ligating the superior pole vessels at a level that avoided possible injury to an external branch of the superior laryngeal nerve, the upper pole was retracted medially and a search made for any possible superior parathyroid gland attached within the thyroid sheath of the upper pole (Fig 8). When found, the parathyroid gland was carefully dissected away from the thyroid pole with efforts made to prevent injuring its blood supply. Extreme care must be used in the identification and dissection of the superior parathyroid gland because the inferior glands may be injured or devascularized during mobilization of the substernal portions of the goiter. In all cases, the superior parathyroid gland or glands, if both sides were removed, were left with an intact blood supply.

The inferior thyroid artery branches were then identified as they entered the thyroid capsule and individually ligated and divided. In some cases, particularly those patients with large goiters extending into the cervical portion of the wound, it was not possible to see the inferior thyroid artery until the substernal component had retracted out of the thoracic inlet. This then allowed further medial mobilization of the cervical portion of the gland. In the usual case, ligation and division of the inferior thyroid artery branches could be accomplished before attempted delivery of the intrathoracic portion of the goiter into the neck (Fig 9).

Once the major arterial supply has been controlled and the gland rotated medially, the recurrent laryngeal nerve (RLN) may or may not be easily identified. It should be noted that the recurrent laryngeal nerve can be located anteriorly or laterally on the surface of the enlarged goiter. More often, the nerve cannot be seen until the substernal component can be retracted medially in the neck. 
FIGURE 6. Occasionally, a nodule within the most posterior extension of the thyroid lobe (tubercle of Zuckerkandl) may grow and enlarge under the RLN, displacing it anteriorly where it is vulnerable to injury. Normally the nerve courses under the tubercle before its entrance into the larynx. On rare occasion, the RLN may be stretched out over the substernal tumor mass causing vocal cord dysfunction or palsy that may or may not recover after thyroidectomy.

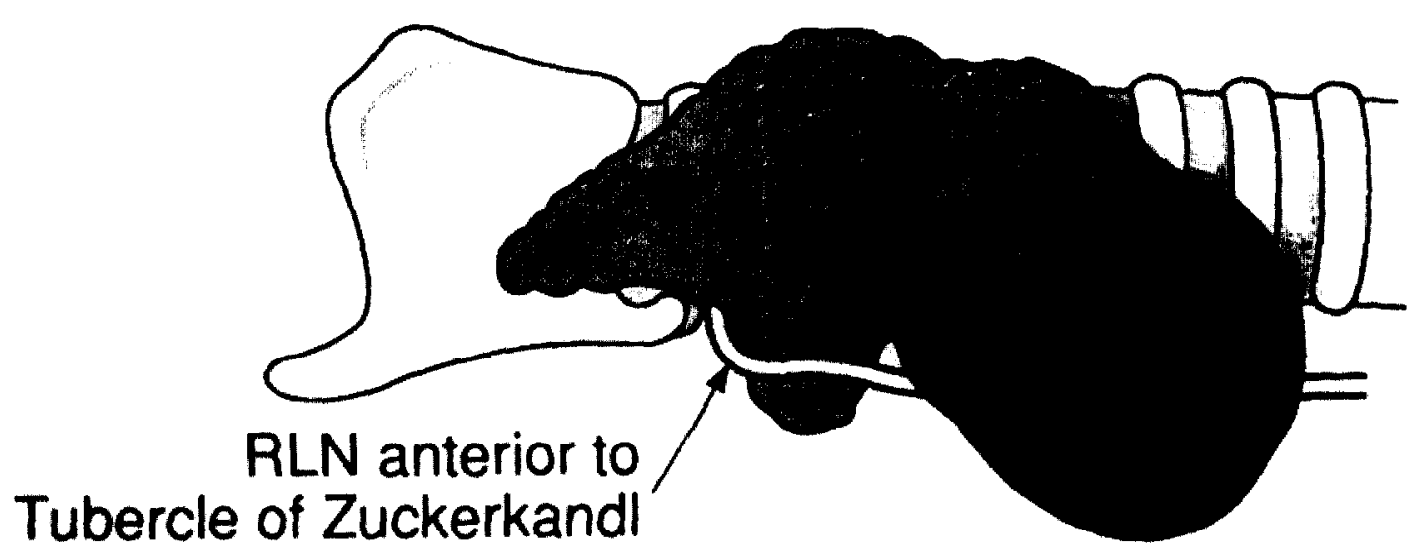

In cases where the goiter is too large for medial rotation, it is obvious that the nerve cannot be seen at all until the substernal component has been retracted from the chest. In either situation, gentle finger dissection is used to free the goiter circumferentially from the surrounding soft tissues, starting anteriorly at the thoracic outlet and proceeding laterally, posteriorly, and inferiorly (Fig 10). This dissection is facilitated by simultaneous traction on the previously mobilized superior pole. As inferior thyroid veins are identified, they are sequentially clamped, divided, and ligated. It is assumed that the middle thyroid vein has been previously identified, divided, and ligated before medial rotation of the upper portion of the

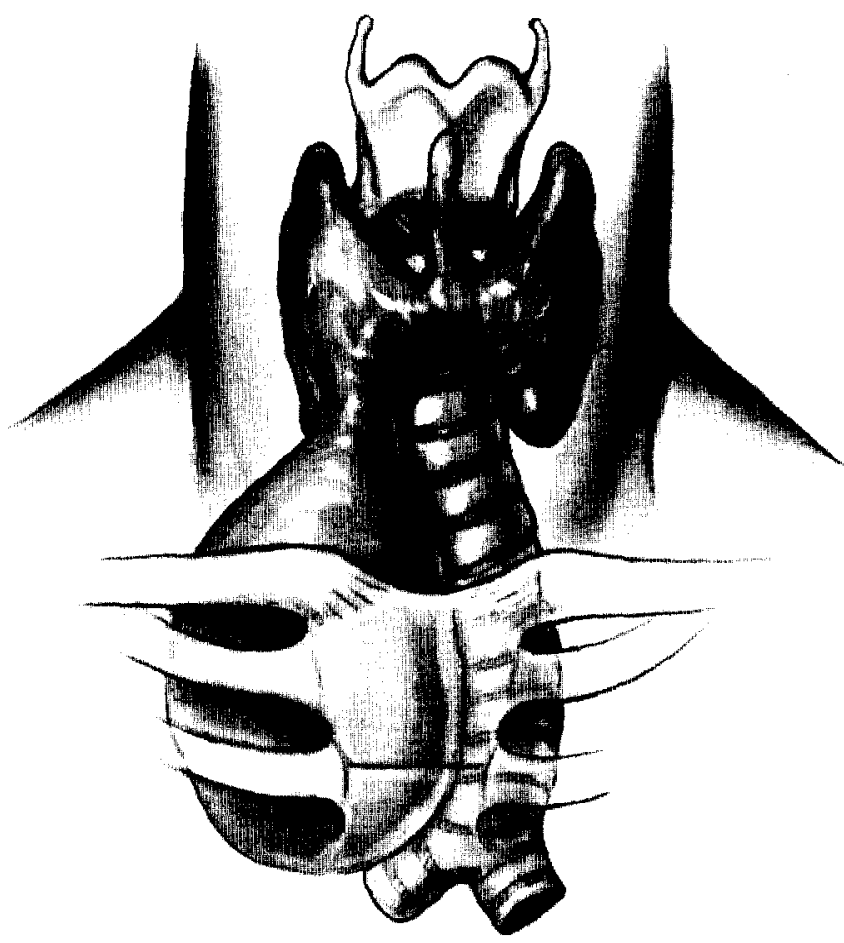

FIGURE 7. "Typical" predominantly intrathoracic goiter on the right side with tracheal deviation to the left. The cervical thyroid may vary in size from near normal to that of an obvious multinodular goiter involving both lobes. On occasion, the contralateral lobe may be free of any palpable nodularity. gland. In cases where the recurrent laryngeal nerve has not been previously identified, care is taken to palpate along the lateral surface of the gland to make sure that the nerve is not stretched on that surface. Usually, the RLN is medial to the substernal portion of the goiter. With the inferior veins divided, the goiter will slowly slip out of the mediastinum with traction. Occasionally, the goiter is so deep that the negative pressure of the chest will prevent this until the suction effect is broken either by the finger or the use of a long sterile soup spoon or a metal

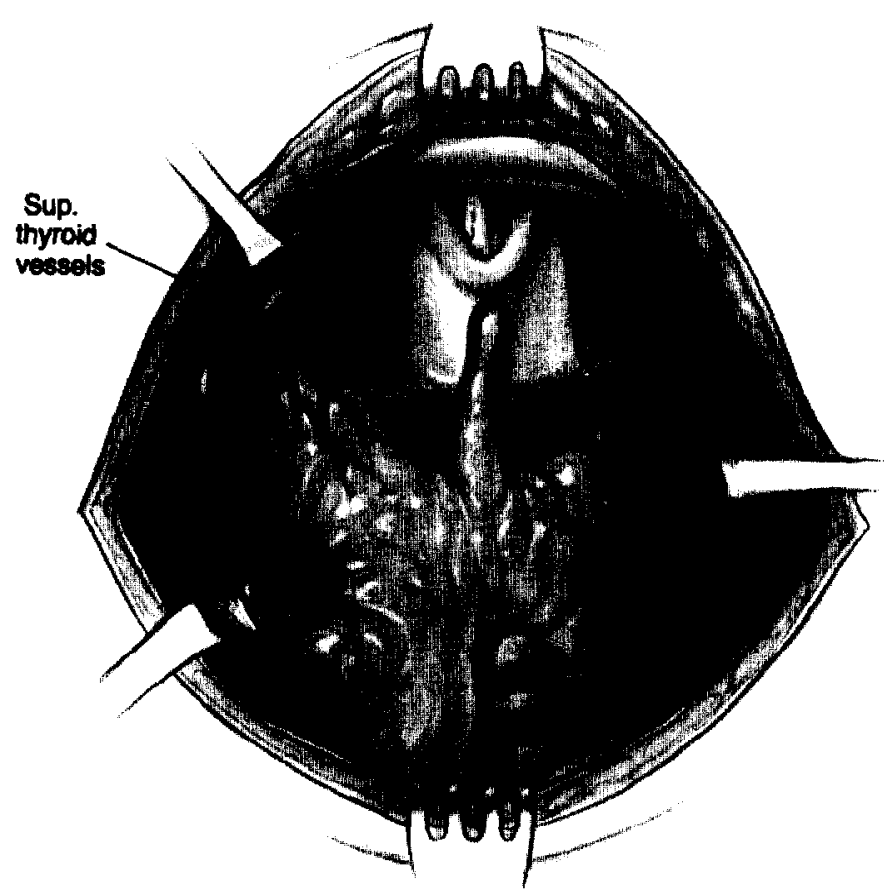

FIGURE 8. The exposure is through a standard collar incision placed two finger breadths above the clavicles. After the anterior suspensory ligament (including any pyramidal lobe) has been divided, the avascular space between larynx and upper pole is entered. With caudal retraction, the superior thyroid vessels are divided between clamps and ligated, avoiding injury to any aberrant external branch of the superior laryngeal nerve. Frequently, the middle thyroid vein is clamped and divided before this is done to further facilitate the downward retraction of the upper pole. 


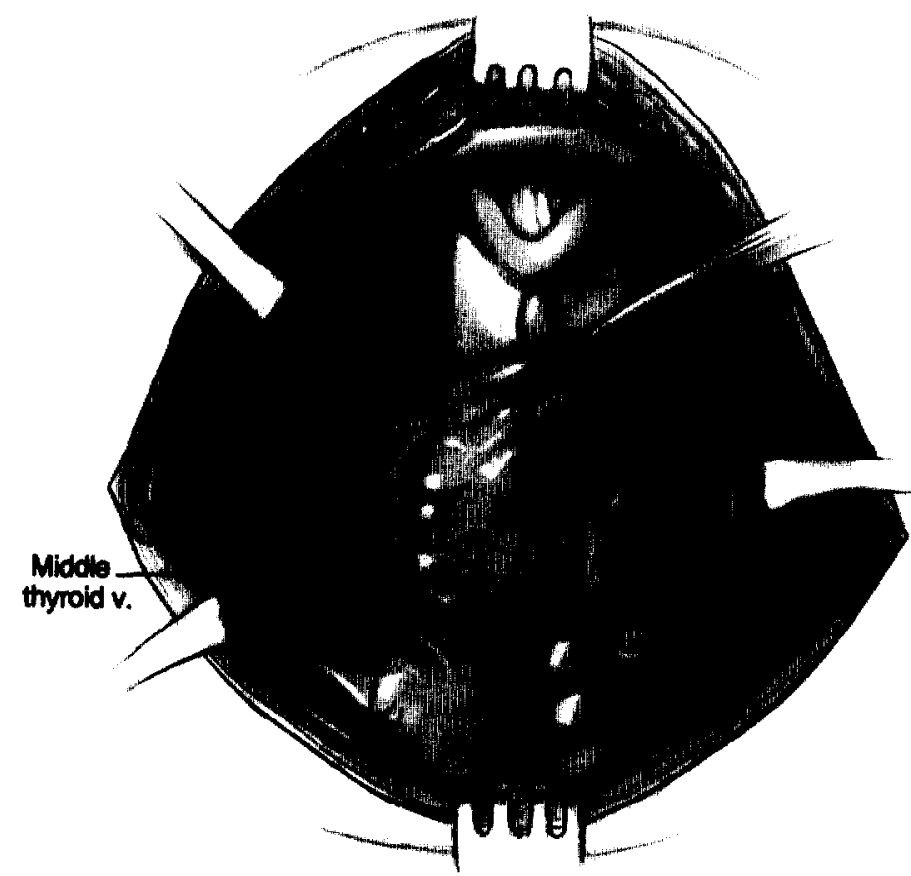

FIGURE 9. After division of the middle thyroid vein(s) and any readily exposed inferior veins, the gland is rotated medially. In some cases in which the cervical thyroid is not grossly enlarged, exposure of the inferior thyroid artery branches allows for their clamping and division at this stage (always medial to possible parathyroid gland blood supply). As the upper pole is rotated medially, the superior parathyroid gland can usually be observed and carefully dissected free of the posterior thyroid capsule if it is attached there. In some cases, exposure of the inferior thyroid artery and RLN is not possible until the intrathoracic component of the lobe has been freed and delivered into the neck.

suction device (Fig 11). Once the substernal component has been brought into the neck, traction on both the inferior and superior pole medially will allow visualization of the region of the tubercle of Zuckerkandl (the most posterior extent of thyroid tissue) and the RLN. If the inferior thyroid artery branches have not been ligated previously, this is done at this time, taking care to visualize the distal course of the RLN before placing clamps (Figs 12 and 13).

In three cases, large, macrocystic, grossly benign goiters were encountered that could not be mobilized from the mediastinum because of their size until they were decompressed. This was accomplished by inserting a long metal suction cannula through a small anterior capsular incision. This allowed evacuation of all the contained fluid and gelatinous material. In each case, the newly decompressed gland was easily removed. This maneuver is obviously contraindicated when a malignant neoplasm is suspected.

When there is a large mediastinal dead space that does not close spontaneously after excision of the goiter, a soft Silastic (Dow-Corning Co, Midland, MI) closed sump drain is placed in the anterior mediastinum and brought out through a separate, small cervical stab incision. The drains are maintained for 24 to 48 hours depending on the volume of evacuated serum.

In patients with elongated or flattened tracheas resulting from the chronic distortion and compression caused by the goiter, the trachea can be tacked anteriorly in the midline to the strap muscles as they are reapproximated in the midline. We have used absorbable sutures for

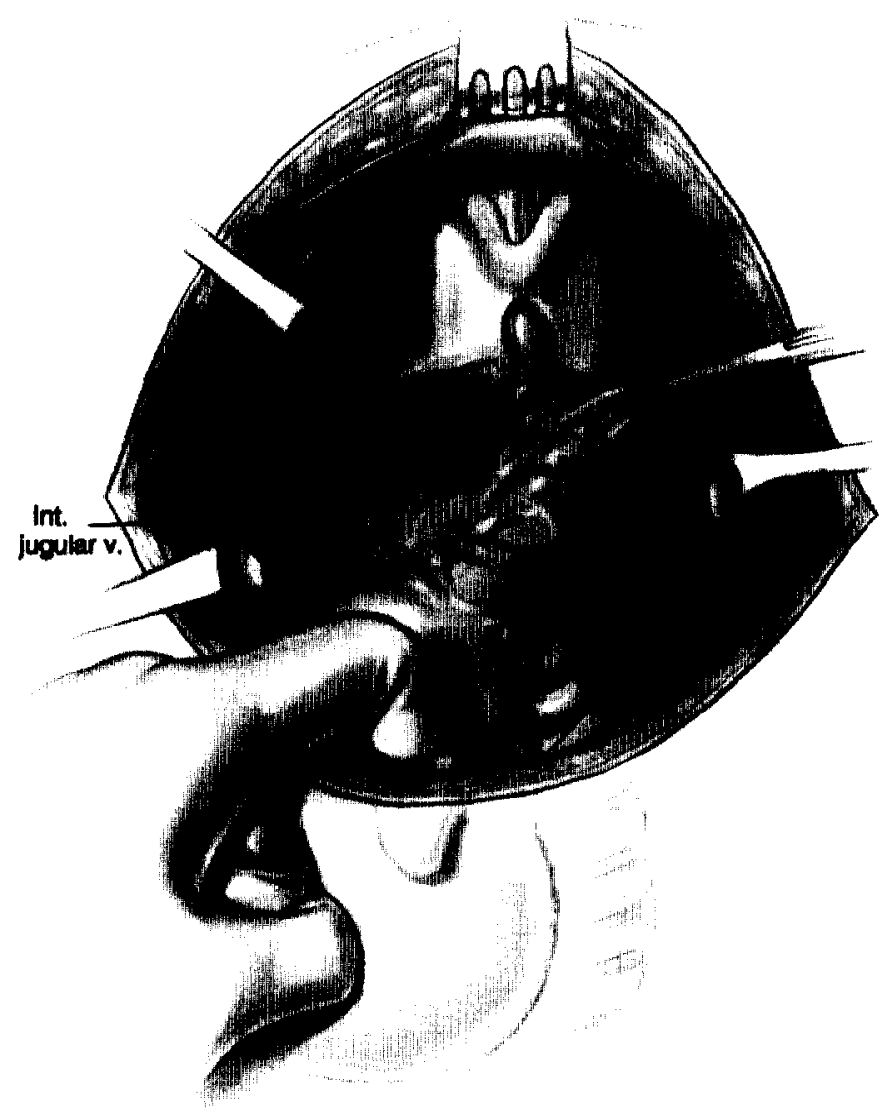

FIGURE 10. Gentle finger dissection around the thyroid capsule while retracting the upper portion of the lobe medially and in a cephalic direction is done, taking great care not to avulse any remaining inferior thyroid veins.

this because the midline suspension is not necessary on a permanent basis. This simple maneuver presents any possibility of postoperative tracheal kinking and airway obstruction based on tracheal laxity (Fig 5).

\section{DISCUSSION}

To fully appreciate the potential complications associated with substernal goiter as well as to make appropriate decisions regarding the evaluation of and the operative approach to substernal goiter, it is essential to understand the anatomy of these enlarged glands.

The large majority of goiters with small substernal extensions are located anteriorly within the visceral mediastinal compartment. They often extend along the undersurface of the sternum to the cephalad aspect of the great vessels. As noted by Shields, ${ }^{14}$ further enlargement of goiters occurs in a caudal direction, subsequently displacing the great vessels dorsally and caudally, and creating the impression that the goiter itself has entered the true anterior or prevascular mediastinal compartment (Fig 14). Dahan et $\mathrm{al}^{15}$ and Sweet ${ }^{16}$ favor the concept of goiter invasion into the anterior mediastinum. However, substernal goiters largely remain beneath the pretracheal fascia, supporting Shield's conclusion that actual descent of a partial or complete substernal goiter into the prevascular compartment is very rare.

There is ongoing controversy regarding the true existence of exclusively intrathoracic goiter arising de novo from developmentally deposited intrathoracic thyroid tissue. Shields ${ }^{14}$ as well as other investigators believe that 


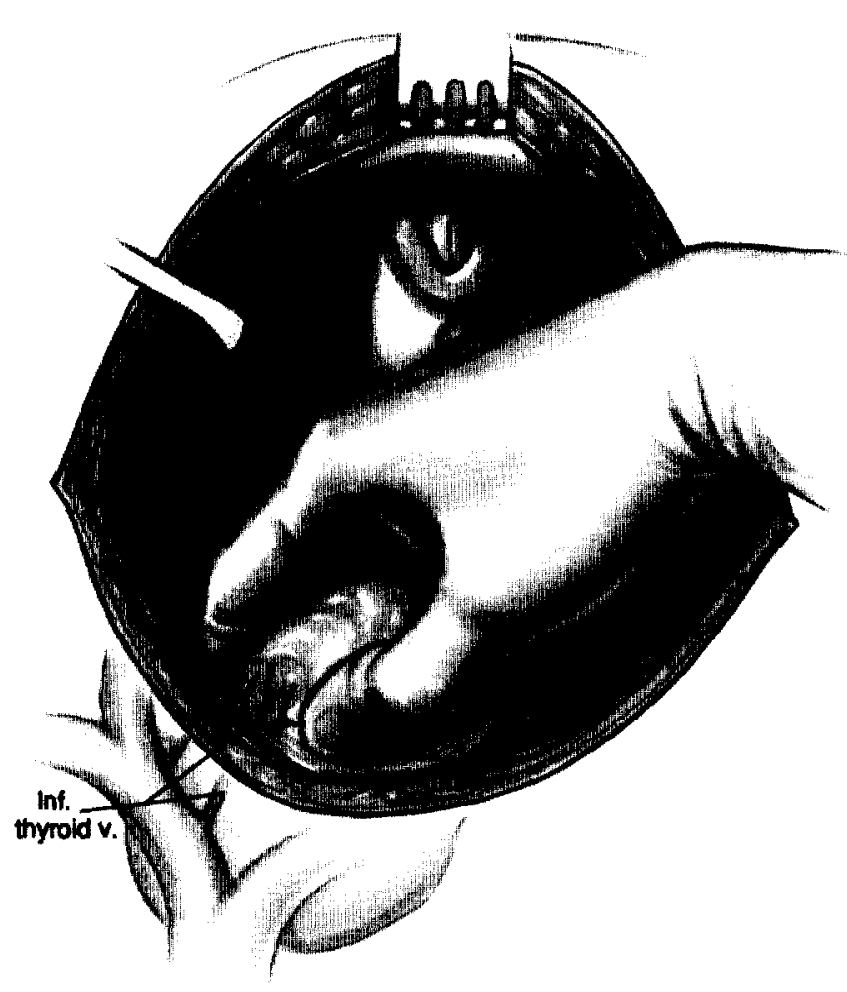

FIGURE 11. With further cephalic retraction and deeper finger dissection, the negative pressure can be broken and eventually the deepest component of the goiter can be felt. Occasionally, it is helpful to use either a soup spoon or large metal suction device inserted lateral and posterior to the deepest portion of the goiter. With medial pressure and slight upward force, a recalcitrant goiter can usually be "released" without too much difficulty.

many of the reported cases of intrathoracic heterotopic or aberrant thyroid goiter ${ }^{17-20}$ actually represent intrathoracic extensions of lower pole cervical goiters that may have subsequently lost parenchymal and/or vascular connection with the cervical thyroid mass.

However, Cove ${ }^{21}$ reports that thyroid tissue can be displaced inferiorly during formation of the embryonic heart, accounting for described associations between foci of thyroid tissue and the aortic arch, the pericardium, and the diaphragm. Furthermore, there are isolated case reports of true ectopic intrathoracic thyroid coexisting with normal cervical thyroid glands. ${ }^{1722-24}$ The patient in this series (as described above) who was found at mediastinal exploration for presumed thymoma to indeed have an intrathoracic goiter with Hurthle-cell carcinoma most likely represented an example of true ectopic intrathoracic goiter. The blood supply to these rare lesions is usually derived directly from the intrathoracic great vessels and we agree with Shields that the optimal treatment for true intrathoracic ectopic goiters is transsternal excision.

Armed with the knowledge that nearly all substernal goiters reside beneath the pretracheal fascia within the visceral mediastinal compartment, it is easy to understand how a superior vena cava obstruction syndrome can develop. As goiters enlarge, most often posterior and medial to the great vessels, the great vessels are progressively compressed anteriorly and laterally against the bony structure of the upper thoracic cage. In actuality, the internal jugular and or innominate veins are most often obstructed with rare involvement of the deeper, more centrally located superior vena cava per se.

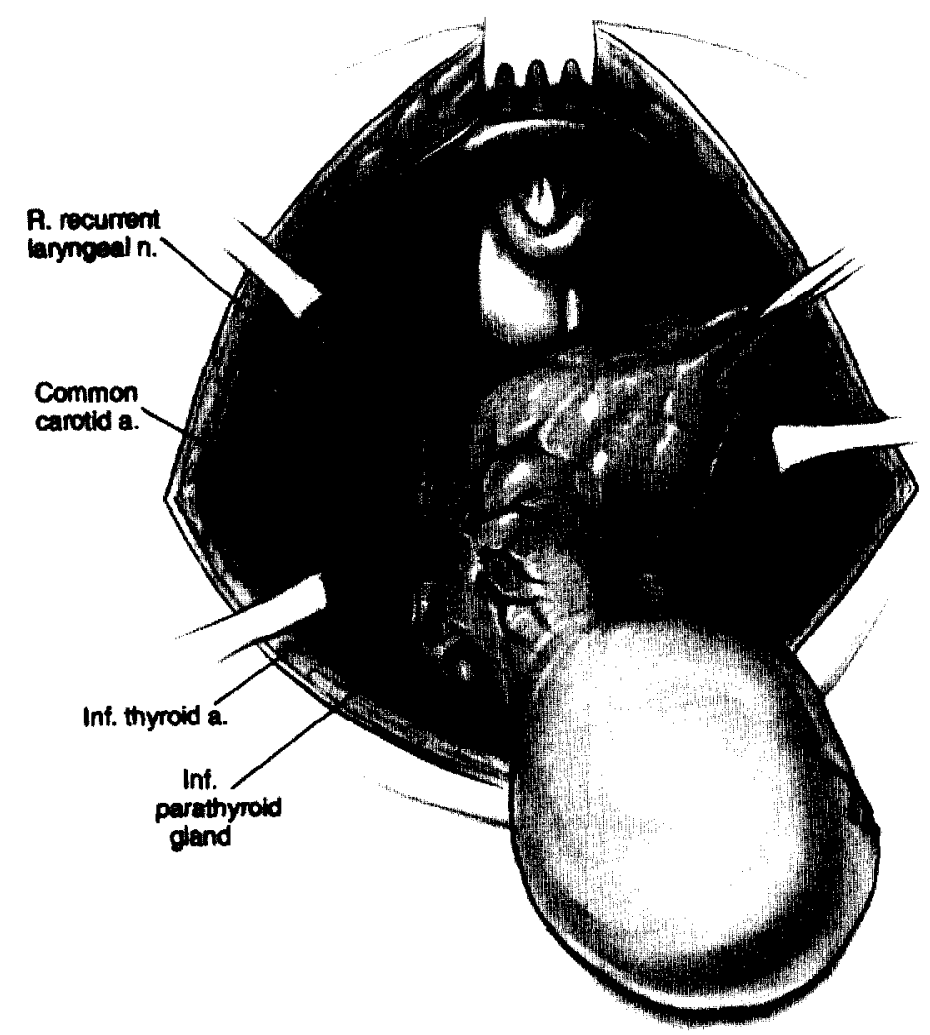

FIGURE 12. As the goiter is retracted into the neck, any remaining veins are clamped, divided, and tied. With retraction of the entire lobe medially, the inferior thyroid artery, its branches, and the RLN can then be readily identified. In patients with benign multinodular goiter, the gland often falls away, exposing these structures without sharp dissection. Division of the individual branches of the inferior thyroid artery, medial to the parathyroid glands, allows the lobe to be retracted medially so that its only remaining attachment is the ligament of Berry.

Presence of a superior vena cava syndrome is an absolute indication for surgical treatment of a substernal goiter. ${ }^{8,25,26}$ Patients with chronic goiter-related venous obstruction can also develop "downhill" esophageal varices that may present with acute upper gastrointestinal bleeding without associated portal hypertension. ${ }^{27,28}$

Perhaps the most critical indication for goiter resection is airway obstruction, which can occur progressively over time as well as acutely. Shaha et al ${ }^{29}$ report that 30 of 120 patients treated for airway problems caused by goiter presented with acute airway compromise requiring hospitalization; 12 of the 30 patients required emergency intubation. Melliere ${ }^{26}$ reports major respiratory compromise in 58 of 2,908 patients with goiter.

A third strong indication for surgical therapy is the inability to accurately exclude carcinoma within the enlarged substernal thyroid. We report a $12.9 \%$ incidence of malignancy, which is within the range of $5 \%$ to $25.8 \%$ reported elsewhere in the literature. ${ }^{9-12,15,26,30}$ Sanders et $\mathrm{al}^{12}$ and Melliere ${ }^{26}$ could find no predictive association between either associated symptoms or duration of goiter and the presence of carcinoma within a substernal goiter. In contrast to the findings of Cady, ${ }^{31}$ Melliere found benign rather than malignant disease to be the principal cause of airway compression. Because of the relatively indolent nature of most thyroid cancers, we agree that the absence of symptoms, particularly voice changes and airway compressive symptoms, and the long-standing presence of a seemingly stable goiter do not preclude malignant disease. 


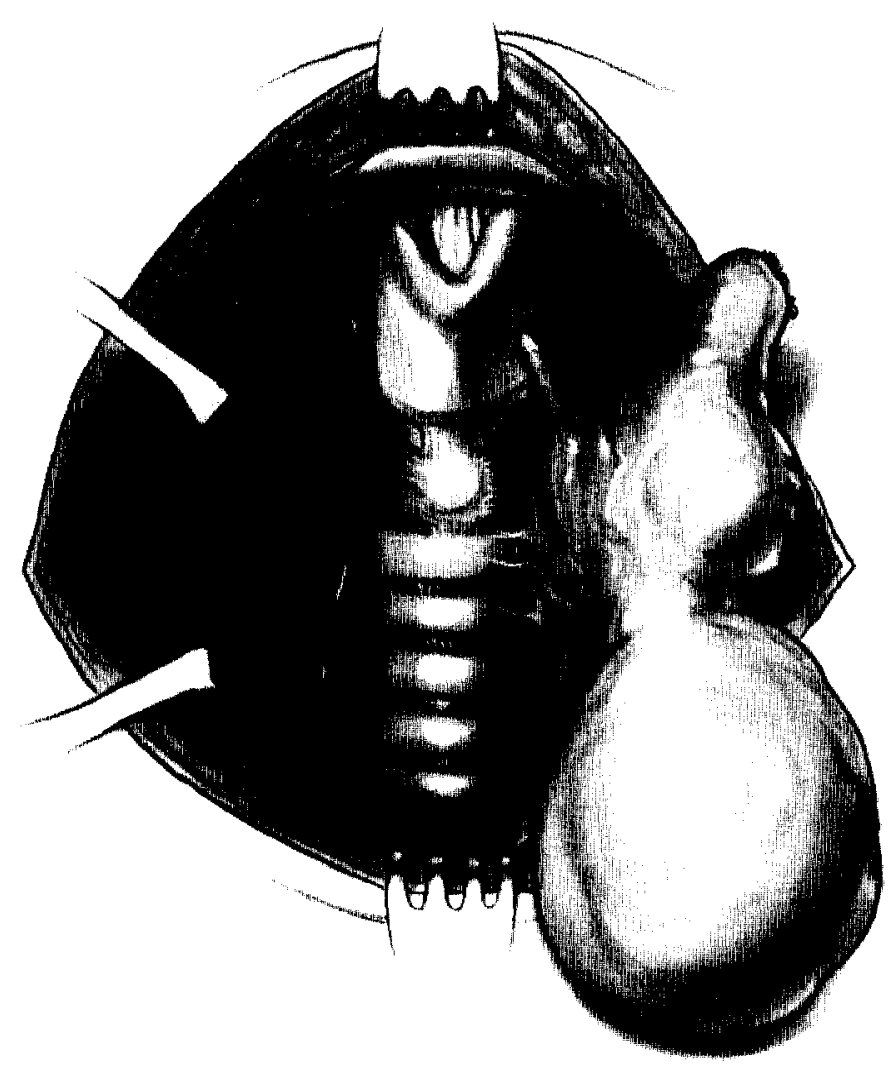

FIGURE 13. After division of the ligament of Berry, the lobe and isthmus are freed from the trachea. In patients with multinodular goiters grossly involving the contralateral lobe, we prefer to proceed with a total thyroidectomy, provided that the parathyroid glands can be easily preserved. Additional indications for a total thyroidectomy include clinically significant thyroid carcinomas within the goiter and toxic nodular goiters.

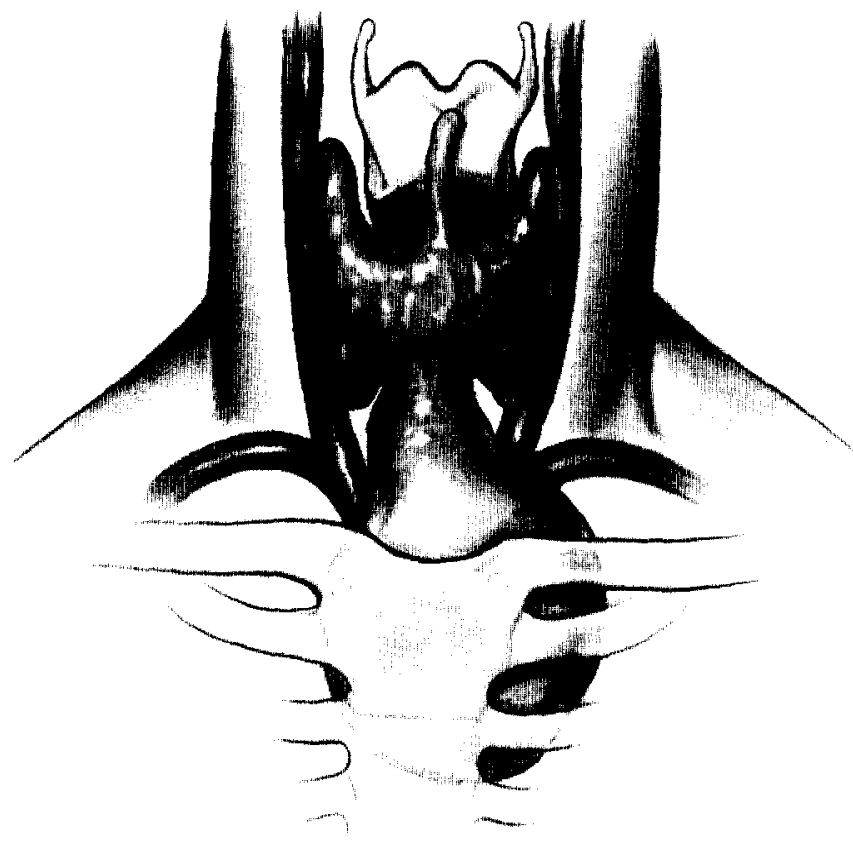

FIGURE 14. Substernal component arising from the isthmus of the thyroid. In such cases there may be no tracheal deviation but significant compression in the anterior-posterior plane causing airway compromise.

Furthermore, there is little value in the use of either radioisotope scanning or fine needle aspiration biopsy to exclude cancer. Although Park et $\mathrm{al}^{32}$ and Irwin et $\mathrm{al}^{33}$ report accurate diagnosis of substernal goiter using ${ }^{131} I$ scintiscanning, Bashist et $\mathrm{al}^{34}{ }^{34}$ Glazer et al, ${ }^{35}$ and Shahian and Rossi $^{36}$ describe poor correlation between radioisotope scanning and operative findings. Based on the experience reported in this series, we agree that the utility of radioisotope scanning is limited at best. Likewise, there is little value to the use of random fine needle aspiration biopsy because large portions of many goiters are inaccessible behind the sternum and the likelihood of sampling error is high.

As previously reported, ${ }^{8}$ some multinodular goiters may result in either incipient or frank thyrotoxicosis. This may occur secondary to discrete, hyperfunctioning nodules within a generally enlarged gland or to an increase in overall functional thyroid tissue mass.

Despite the widespread use of suppressive levothyroxine, which undoubtedly has altered the incidence of goitrogenic growth, there is clearly a subset of patients with long-standing substernal goiter that fails to respond to levothyroxine suppression. ${ }^{12,28,37-42}$ Nearly half of the patients in this series had been placed on thyroidsuppressive therapy without success before referral for surgery.

Although radioactive iodine ablation therapy had been successfully used in other thyroid disease states, it has rarely been shown to alleviate either tracheal deviation or compression caused by large multinodular goiter. ${ }^{43}$ LeRoux et $\mathrm{al}^{44}$ report that administration of ${ }^{131} \mathrm{I}$ may, in fact, induce temporary radiation thyroiditis, exaggerating preexisting airway compromise. We consider radioactive iodine contraindicated whenever compression symptoms are present.

Resection of substernal goiter is the only viable treatment option. We do not agree with Lamke et $\mathrm{al}^{45}$ who write that "with scintigraphy and aspiration biopsy, many of these cases can safely be left without operation and thus the number of diagnostic and prophylactic extirpations can be greatly reduced."

During the past 10 years, all patients with airway compression symptoms with the exception of those few requiring emergent endotracheal intubation when first seen, were evaluated electively in a "Difficult Airway Clinic" by an anesthesiologist with a special interest and expertise in intubation problems. In selected cases, a variety of special radiographic and pulmonary function studies and laryngeal examinations were performed and specific recommendations made about technique and type of anesthesia to be used. Heliox was used in those patients who were recommended for an awake intubation. In several patients, heliox was administered for 12 or more hours while awaiting an elective or urgent rather than emergent procedure. It is estimated that the decreased viscosity of this mixture of gases allows up to five times the delivery of oxygen to the lungs with each breath compared with room air.

Nearly all substernal goiters can and should be removed via a low transverse collar cervical incision. Ninety-seven percent of goiters in this series were successfully removed through this approach; many other authors $3,7,26,28,42,46$ report similar success (92\% to $100 \%)$. In no instance did we find it necessary to combine the cervical approach with an anterolateral thoracotomy as recommended by DeAndrade ${ }^{7}$ or Johnston and Twente. ${ }^{47}$ The 6 patients with largely posterior mediastinal goiters were also successfully treated through an anterior collar incision (Fig 15). None required a posterolateral thoracotomy as advocated by Sweet ${ }^{16}$ and Ellis et al. ${ }^{48}$ Excluding the single patient with the intrathoracic goiter with Hurthle-cell carcinoma, only 2 patients required a 
FIGURE 15. Anteriorposterior view of leftsided posterior substernal goiter with the major component dissecting between the trachea and the esophagus. These patients may have both dysphagia and compromised airway symptoms. Extra care must be taken not to injure the RLN when delivering the tumor from the thorax.

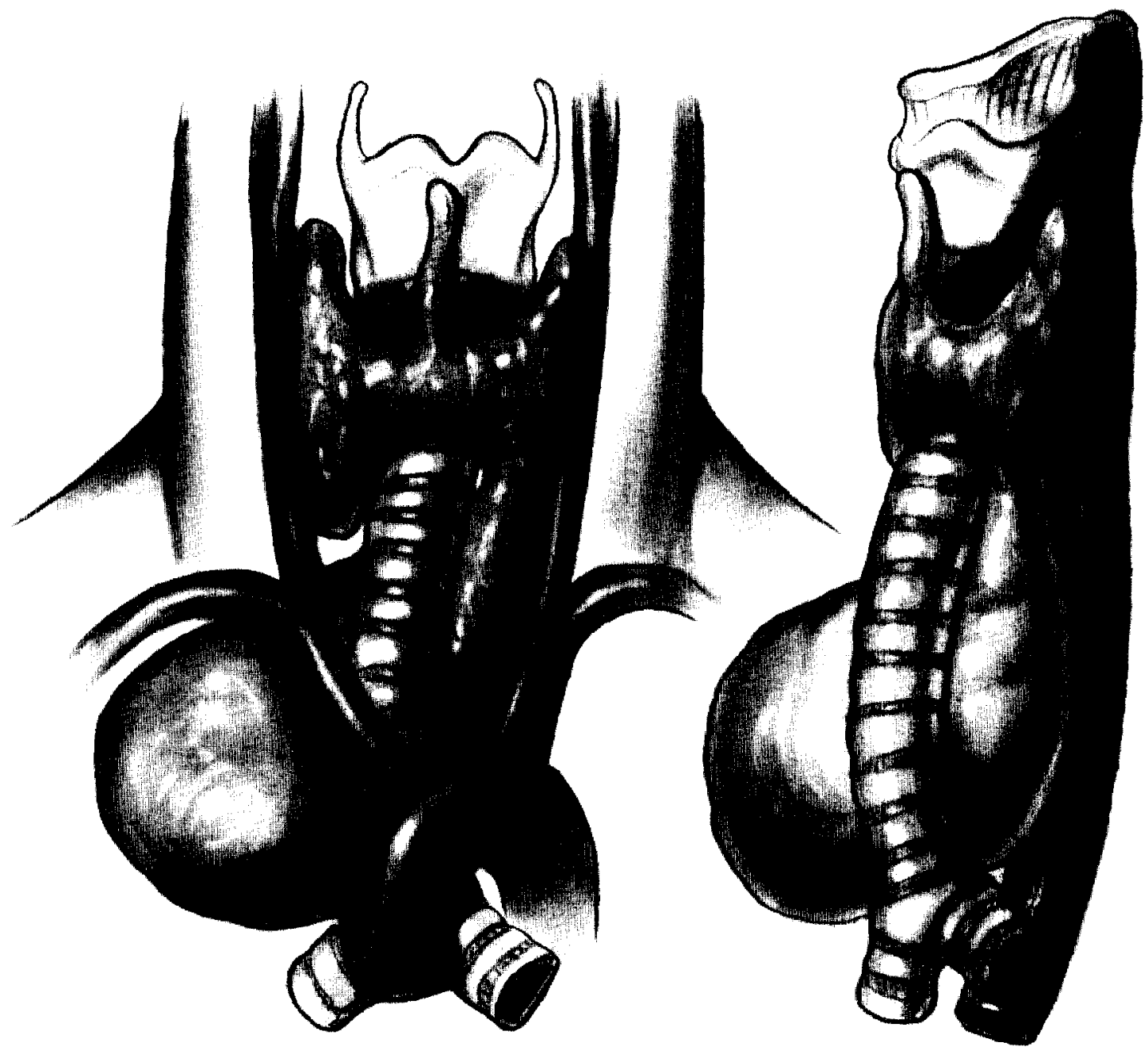

partial sternal split, using the technique described by Lilienthal. ${ }^{49}$

With the exception of the unusual, large primary malignant neoplasm, substernal thyroid enlargements are caused by multinodular colloid goiters. Not infrequently, there are also nodules within the isthmus or contralateral lobe that have remained in a cervical location. Where multiple palpable nodules are present, we currently prefer to perform a total or near total thyroidectomy to prevent future recurrence of either cervical or substernal goiter. A significant number of our cases represent recurrent goiter many years after a previous lobectomy or subtotal thyroidectomy, often despite thyroid replacement therapy. It is apparent that nodules larger than 1 or $2 \mathrm{~cm}$ in diameter are often autonomous in growth and are not influenced by hormone suppression. Lobectomy and isthmusectomy appear to be successful where there are no palpable or dominant nodules within the remaining thyroid lobe. We have had no recurrent goiters in any of our patients during the past 20 years. However, as noted previously, $75 \%$ of our patients have had a total thyroidectomy during the last 10 years of this study. We consider total thyroidectomy to be the treatment of choice whenever a clinically significant papillary carcinoma $(1 \mathrm{~cm})$, medullary, Hurthle-cell, or follicular carcinoma is diagnosed at operation, even when the contralateral lobe is normal to palpation.

Finally, surgical therapy should be regarded as a safe procedure with rare associated mortality and minimal morbidity. DeAndrade ${ }^{7}$ reports an operative mortality of $0.7 \%$ and Dahan et $\mathrm{al}^{15}$ report a mortality rate of $2.8 \%$. There were no operative deaths in this series. Our reported $2 \%$ incidence of permanent unilateral vocal cord paralysis is in keeping with the $6 \%$ and $10 \%$ reported by Dahan et $\mathrm{al}^{15}$ and Watt-Boolen et al, ${ }^{50}$ respectively. In this series, there was no added morbidity from total thyroidectomy as there were no RLN injuries on the side contralateral to the substernal component. None of our patients sustained permanent hypoparathyroid injury following surgery.

In conclusion, substernal multinodular goiter should be treated with primary resection because there is no effective medical therapy available. Respiratory compromise, thyrotoxicosis, and dysphagia are major complications associated with substernal goiter and can develop insidiously or acutely even in goiters of long-standing duration. Furthermore, there is no reliable method to accurately exclude the presence of malignancy in those diagnostically inaccessible glands. Nearly all goiters can be removed through a cervical incision with relatively low morbidity and mortality.

\section{REFERENCES}

1. Shambaugh E, Seed R, Korn A: Airway obstruction in substernal goiter: Clinical and therapeutic implications. J Chronic Dis 26:737743, 1973

2. Lahey F, Swinton N: Intrathoracic goiter. Surg Gynecol Obstet 59: 627-637, 1934

3. Wakeley C, Mulvany J: Intrathoracic goiter. Surg Gynecol Obstet 70:702-710, 1940

4. McCort JJ: Intrathoracic goiter: Its incidence, symptomatology and roentgen diagnosis. Radiology 53:227-237, 1949

5. Pemberton J: Surgery of substernal and intrathoracic goiters. Arch Surg 71:347-356, 1955 
6. Reeve T: Intrathoracic goiter: Investigation and management. Proceedings of the First Asian Congress on Thoracic and Cardiovascular Surgery, Manila, The Philippines, 1977, p 789

7. DeAndrade MA: A review of 128 cases of posterior mediastinal goiter. World J Surg 1:789-797, 1977

8. Allo MD, Thompson NW: Rationale for the operative management of substernal goiters. Surgery 94:969-977, 1983

9. Shaha AR, Alfonso AE, Jaffe BM: Operative treatment of substernal goiters. Head Neck 11:325-330, 1989

10. Maruotti RA, Zannini P, Viani MP, et al: Surgical treatment of substernal goiters. Int Surg 76:12-17, 1991

11. Wax MK, Briant TD: Management of substernal goiters. J Otolaryngol 21:165-170, 1992

12. Sanders L, Rossi R, Shahian D, et al: Mediastinal goiters: The need for an aggressive approach. Arch Surg 127:609-613, 1992

13. Lahey F: Intrathoracic goiters. Surg Clin North Am 25:609-618, 1945

14. Shields $T$ : Lesions masquerading as primary mediastinal tumors or cysts, in Shields T (ed): Mediastinal Surgery. Philadelphia, PA, Lea \& Febiger, 1991, pp 118-137

15. Dahan M, Gaillard J, Eschapasse $H$ : Surgical treatment of goiters with intrathoracic development, in Delarue N, Eschapasse H (eds): International Trends in General and Thoracic Surgery, vol 5: Thoracic Surgery: Frontiers and Uncommon Neoplasms. St Louis, MO, Mosby, 1989

16. Sweet R: Intrathoracic goiter located in the posterior mediastinum. Surg Gynecol Obstet 89:57-66, 1949

17. LeRoux BT: Heterotopic mediastinal thyroid. Thorax 16:192-506, 1961

18. Dundas P: Intrathoracic aberrant goiter. Acta Chir Scand 128:729736,1964

19. Nwafo DC: Heterotopic mediastinal goiter. Br J Surg 65:505-506, 1978

20. Hall TS, Caslowitz $P$, Popper $C$, et aI: Substernal goiter versus intrathoracic aberrant thyroid: A critical difference. Ann Thorac Surg 46:684-685, 1988

21. Cove $\mathrm{H}$ : The mediastinum, in Coulson $\mathrm{W}$ (ed): Surgical Pathology (ed 2). Philadelphia, PA, Lippincott, 1988

22. Salvatore $M$, Gallo $A$ : Accessory thyroid in the anterior mediastinum: Case report. J Nucl Med 16:1135-1136, 1975

23. Sussman SK, Silverman PM, Donnal JF: CT demonstration of isolated mediastinal goiter. J Comput Assist Tomogr 10:863-864, 1986

24. Rives JD: Mediastinal abberant goiter. Ann Surg 126:797-810, 1947

25. Katlic MR, Wang C, Grillo HC: Substernal goiter. Ann Thorac Surg 39:391-400, 1985

26. Melliere D, Saada F, Etienne $G$, et al: Goiter with severe respiratory compromise: Evaluation and treatment. Surgery 103:367-373, 1988

27. Kelly TR, Mayors D, Botsicaris PS: Downhill varices: A cause of upper gastrointestinal hemorrhage. Am Surg 48:35-38, 1982

28. Sorokin J, Levine SM, Moss EG, et al: Downhill varices: Report of a case 29 years after resection of a substernal thyroid gland. Gastrocnterology 73:345-348, 1977
29. Shaha A, Burnett C, Alfonso A, et al: Goiters and airway problems Am J Surg 158:378-381, 1989

30. Michel LA, Bradpiece HA: Surgical management of substernal goiter. Br J Surg 75:565-569, 1988

31. Cady B: Management of tracheal obstruction from thyroid disease. World J Surg 6:696-701, 1982

32. Park H, Tarver RD, Siddiqvi AR, et al: Efficacy of thyroid scintigraphy in the diagnosis of intrathoracic goiter. Am J Roentgen 148: 527-529, 1987

33. Irwin $R$, Braman $S$, Arvanitidis A, et al: 131 Iodine thyroid scanning in preoperative diagnosis of mediastinal goiter. Ann Intern Med 89:73-74, 1978

34. Bashist B, Ellis $\mathrm{K}$, Gold R: Computed tomography of intrathoracic goiters. Am J Roentgen 140:455-460, 1983

35. Glazer $G$, Axel $L$, Moss A: CT diagnosis of mediastinal thyroid. Am J Roentgen 138:495-498, 1982

36. Shahian D, Rossi RL: Posterior mediastinal goiter. Chest 94:599-602, 1988

37. Geerdsen J, Forlund L: Recurrence of nontoxic goiter with and without postoperative thyroxine medication. Clin Endocrinol 21:529-533, 1984

38. Gharib H, James E, Charboneau J, et al: Suppressive therapy with levothyroxine for solitary thyroid nodules: A double blind controlled clinical study. N EngI J Med 317:70-75, 1987

39. Welch C: Therapy for multinodular goiter. JAMA 195:95-97, 1966

40. Lindem M, Clark J: Indications for surgery in thyroiditis. Am J Surg 118:829-831, 1960

41. Sedgwick C: Nontoxic nodular goiter, in (ed): Surgery of the Thyroid Gland: Major Problems in Clinical Surgery. Philadelphia, PA, Saunders, 1974

42. Katlic $M$, Wang $C$, Grillo $H$ : Substernal goiter-An analysis of 80 patients from Massachusetts General Hospital. Am J Surg 149:283287,1985

43. Beierwalters $W$ : The treatment of hyperthyroidism with iodine 131 . Semin Nucl Med 8:95-103, 1978

44. LeRoux B, Kallichurum S, Shama D: Mediastinal cysts and tumors. Curr Probl Surg 21:11, 1984

45. Lamke L, Bergdahl L, Lamke B: Intrathoracic goiter: A review of 29 cases. Acta Chirurg Scand 145:83, 1979

46. Cho H, Cohen J, Som M: Management of substernal and intrathoracic goiters. Otolaryngol Head Neck Surg 94:282, 1986

47. Johnston J, Twente G: Surgical approach to intrathoracic (mediastinal) goiter. Ann Surg 143:572-579, 1956

48. Ellis F, Good C, Seybold W: Intrathoracic goiter. Ann Surg 135:7990, 1952

49. Lilienthal $\mathrm{H}$ : A case of mediastinal thyroid removed by transsternal mediastinotomy. Surg Gynecol Obstet 20:589-593, 1915

50. Watt-Boolen $S$, Blichert-Toft M, Folke K, et al: Surgical treatment of benign nontoxic intrathoracic goiter. Am J Surg 141:721-722, 1981 